\title{
Preditores de hiperacusia na migrânea
}

\section{Bruna Colomera Maistro ${ }^{D}$, Ana Clara Oliver Machado ${ }^{D}$, Beatriz Bagatim Bossa ${ }^{D}$, Valéria Aparecida Bello $(\mathbb{D}$, Regina Célia Poli Frederico , Aline Vitali da Silva}

Pontifícia Universidade Católica do Paraná, Curitiba, Paraná, Brasil.

\section{Introdução}

A fonofobia é um sintoma comum e compõe o critério diagnóstico de migrânea, no entanto a hiperacusia ainda foi pouco estudada no contexto da migrânea.

\section{Objetivo}

Avaliar a prevalência e os preditores de hiperacusia em pacientes com migrânea.

\begin{abstract}
Metodologia
Estudo prospectivo do tipo caso-controle composto por pacientes com migrânea. Os participantes responderam entrevista estruturada sobre dados demográficos, antropométricos e características clínicas da migrânea. Também responderam questionários validados sobre depressão (IDB), ansiedade (STAIY2), incapacidade (MIDAS), alodinia (ASC-12) e ao questionário de hiperacusia. Foi considerado que o participante tinha hiperacusia quando tivesse pontuação $\geq 22$ no questionário de hiperacusia. A pesquisa foi aprovada pelo Comitê de Ética em Pesquisa $\left(\mathrm{n}^{\circ}\right.$ 3.029.972).
\end{abstract}

\section{Resultados}

O questionário foi respondido por 276 pacientes com migrânea, dos quais 237 do sexo feminino, 171 com migrânea episódica e 106 com aura. Em análise univariadas a hiperacusia foi associada a migrânea crônica $(O R=2,28$; $p=0,001)$, fonofobia $(O R=2,56 ; p=0,017)$, osmofobia $(O R=2,97 ; p<0,001)$, alodinia $(O R=2,91 ; p<0,001)$, ansiedade $(O R=10,57 ; p=0,007)$, depressão $(O R 2,89 ; p=0,002)$ e incapacidade relacionada a migrânea $(O R=2,81$; $p=0,002)$. Após regressão logística binária, permaneceram associados a hiperacusia: a forma crônica da migrânea $(\mathrm{OR}=2,03 ; \mathrm{p}=0,019)$, osmofobia $(\mathrm{OR}=2,2 ; \mathrm{p}=0,022)$ e maior incapacidade relacionada a migrânea $(\mathrm{OR}=2,5$; $\mathrm{p}=0,022$ ). Idade, gênero, obesidade, aura e fotofobia não se associaram a hiperacusia.

\section{Conclusão}

A forma crônica, osmofobia e maior incapacidade foram preditores de hiperacusia em indivíduos com migrânea.

Palavras-chave: Hiperacusia, Fonofobia, Migrânea 